\title{
NOTÍCIAS DA REPÚBLICA BRASILEIRA, E DA QUEDA DE UM IMPERADOR, NOS PERIÓDICOS PORTUGUESES DO SÉCULO XIX
}

\author{
Eduardo Melo França* \\ eduardomelofranca@hotmail.com
}

RESUMO: Pretende esse artigo mapear algumas das principais notícias publicadas entre os principais periódicos portugueses do século XIX sobre a instalação da república brasileira e a queda de Pedro II.

PALAVRAS-CHAVE: Pedro II; república brasileira; imprensa portuguesa.

No final do século XIX, a passagem da monarquia para a república representava a transição do velho para o novo e do poder centralizado para a democracia. Nas Américas, entre revoltas, revolução e guerrilhas, a república ia gradualmente tomando conta do continente. Do outro lado do oceano, Portugal ainda era uma monarquia que, mesmo antes do assassinato de D. Carlos e do breve e conturbado governo de Dom Miguel II, já sentia ansioso o aroma da república. Foi nesse clima de monarquia desgastada e de desejo republicano que os periódicos portugueses noticiaram a república brasileira.

As notícias sobre a proclamação da república no Brasil, publicadas entre os principais periódicos culturais portugueses, no final do século XIX, nos dão a impressão de que o personagem principal de toda essa repercussão foi menos o Brasil, sua política, monarquia e república, e mais, muito mais, Dom Pedro II. Como veremos, quase todas as linhas escritas sobre o tema serviram de motivo para elogiar aquele que ficou conhecido como o "imperador filósofo" ou para lamentar a forma abrupta, ainda que não violenta - e até cordial, de como se deu a sua destituição. Mesmo os comentaristas que acreditavam ser natural e inevitável a chegada da república, esperavam que essa mudança somente ocorresse com a morte do

\footnotetext{
* Doutor em Teoria da Literatura pela UFPE.
} 
monarca. Não estaríamos exagerando se disséssemos que algumas dessas notícias, inclusive, trataram a "revolução" republicana brasileira menos como uma grande mudança no cenário político e econômico brasileiro e mais como um desrespeito e falta de consideração pelo imperador, que durante todo o seu reinado foi capaz de manter unido e em paz o Brasil.

Em 1887, obviamente antes da instauração da república tupiniquim, em visita a Portugal, para se consultar com médicos especialistas, Dom Pedro recebeu da imprensa afagos, pelos seus laços com Portugal, e serviu, simultaneamente, de mote para especulações sobre a onda republicana que se fortalecia na Europa. "Este monarca", disse Mariano Pina, na Ilustração: Revista Quinzenal para Portugal e o Brasil, "é um português de sangue - é o filho de Pedro IV, o Libertador; e é um brasileiro de adoção (...) Tão ardente simpatia conta no país de que é o chefe supremo como em Portugal, onde é recebido em compatriota" (PINA, 1887, p. 242). Dom Pedro, que nas palavras do articulista é "um imperador metido na pele de um filósofo", reflete em cada um dos seus atos respirar os conselhos do moralista Jean de La Bruyère. Diante das ameaças republicanas que assolavam a Europa, e que partiam com força principalmente da França, o monarca teria dado um exemplo de "grande equidade e de grande justiça a todos os seus colegas da Europa, vindo à França, vindo a Paris, e comprazendo-se em passar aqui alguns dias na companhia de amigos velhos como Chevreul, como Pasteur e como Lesseps" (PINA, 1887, p. 242). E o articulista prossegue:

Devemos confessar que é realmente simpático ver um imperador autêntico, de carne e osso, o imperador de um vasto e rico mundo império da América, entrar em Paris como o mais simples dos homens e o mais curioso dos touristes, e em homem apaixonado por tudo quanto apaixona Paris (...) (PINA, 1887, p, 242).

Num artigo escrito anteriormente por Júlio de Mattos, por motivo da publicação do livro de Alberto Sales, Política Republicana, e saído em 1882 no periódico O Positivismo: Revista de Filosofia, lemos um elogio à forma como os republicanos pareciam se organizar e caminhar para a definitiva instalação de um novo regime no Brasil:

É notável o movimento democrático atual no Brasil. Notável não tanto pela energia e atividade, que aliás são grandes, como pelo caráter eminentemente positivo que o caracteriza. Não é uma agitação indisciplinada um aspirar inconsciente e anárquico e reformas políticas e sociais, o que aí se observa; é sim, uma forte opinião radicada, metodicamente posta à luz com a coragem serena e paciente, a mais poderosa de todas as coragens, emana da ciência e alimentada por um forte patriotismo. Parece que no Brasil, como entre nós, soou a hora de morte para os utopistas e agitadores e por isso mesmo também para as velhas instituições (MATTOS, 1882, p. 246).

Hist. R., Goiânia, v. 18, n. 2, p. 169-185, jul. / dez. 2013 
Em 1889, na Ilustração: Revista Quinzenal para Portugal e o Brasil, um artigo, não assinado, destaca dois aspectos da revolução no Brasil. O primeiro, que foi um movimento que teve adesão do "Exército, [d]a Marinha, [d]os principais funcionários do Estado, e [d]a sua população fluminense". Depois, diante do respeito imposto pela figura do imperador:

Uma característica desta revolução que muito honra os republicanos brasileiros, é que nenhum dos que intimaram D. Pedro II para partir para a Europa se lembrou de empregar uma palavra hostil contra o imperador chegando até a asseverar-lhe que lhe seria garantia a sua lista civil até ao fim dos seus dias diz que ofereceram 5000 contos (francos) para sua despesa de viagem (A REPÚBLICA DOS ESTADOS UNIDOS DO BRASIL, 1889, p. $358)$.

Lemos no mesmo artigo que "nunca uma revolução contra um chefe de estado apresentou um caráter tão conciliador, tão amável e tão respeitoso”. Fica a sugestão de que o caráter pacífico dessa revolução muito se deveu à postura elegante de Dom Pedro, que diante da "gravidade dos acontecimentos (...) para evitar os horrores de da guerra civil, teve de ceder e de partir para a Europa (...)". Deve-se ainda destacar que foi visto como elegante, digno e coerente com sua história pessoal e familiar, o fato do imperador não ter aceito o dinheiro oferecido pelos próprios revolucionários para custear sua viagem.

Também na Ilustração, num artigo escrito em 1889, Latino Coelho se preocupou em recolher a opinião de algumas importantes figuras do cenário político e cultural português. Dentre esses nomes estava o de Pinheiro Chagas, que considerava o novo regime no Brasil como uma consequência natural do reinado de Dom Pedro - "não nos assusta a república brasileira, e estávamos vendo há muito que seria ela quase inevitavelmente a herdeira de D. Pedro II" (PINHEIRO CHAGAS apud COELHO, 1889, p. 363). Mas não foi a chegada da república que mais lhe despertou atenção. Pinheiro Chagas deu especial destaque ao fato de que a revolução interrompia abruptamente os últimos dias do reinado de Dom Pedro, ao mesmo tempo em que não se dava pelas mãos de figuras preparadas e à altura do imperador:

Mas lamentamos deverás que uma revolução de caserna, passando por cima amargurasse da própria vontade dos republicanos, com esta insânia, os últimos dias de um glorioso reinado, os últimos das de um soberano que o próprio Quintino Bocaiuva chama como vimos de "o imperador filósofo". Lamentamos que o Brasil entre na república, não pela mão de um Washington e de um Franklin, como os gloriosos Estados Unidos, mas pela mão dos chefes dos pronunciamentos que durante cinquenta anos mancharam de sangue o noviciado das repúblicas espanholas, e entorpeciam o seu natural progresso. 
Mas inclinar-nos-emos diante da vontade do povo brasileiro, e não entibia o nosso afeto a essa nação, essa quase inexplicável mutação à vista o Brasil tem o pleno direito, que respeitamos, de escolher as instituições que quiser, e no momento que julgar oportuno; mas lamentamos que a república atropele no seu carro avante o augusto velho, que foi e que será sempre, imperador das mais puras glórias do Brasil (Pinheiro Chagas apud COELHO, 1889, p. 363).

Latino Coelho destaca que no jornal $O$ Dia, que funcionava sob a direção política de Antonio Ennes, lemos que a "revolução" no Brasil "expulsou do trono o soberano que foi penhor da independência do Brasil, defensor da sua liberdade e promotor diligente dos seus progressos morais e materiais" (apud COELHO, 1889, p. 363).

Já no jornal O Tempo, dirigido por Carlos Lobo d'Avila, Oliveira Martins, primeiro, questiona "que novas liberdades, que novas garantias, que novas vantagens positivas vai a república dar ao Brasil, caso uma reação do bom senso não abafe o movimento que se anuncia vitorioso? Nenhum. Nem um só” (OLIVEIRA MARTINS apud COELHO, 1889, p. 366). A revolução no Brasil, diz Oliveira Martins, não seria outra coisa senão um "erro funesto". Afinal, "foi com o império que venceu" Montevidéu e o Paraguai. Foi somente com o império, diz Oliveira Martins, que o Brasil teve meio século de paz "interna inalterada", que criou o Exército, a Marinha e que multiplicou as escolas, que construiu a rede das estradas e caminhos de ferro e que protegeu as lavouras indígenas. Foi o império, arremata ele, "que aboliu a escravidão" (Oliveira Martins apud COELHO, 1889, p. 366). Oliveira Martins foi outro que não se surpreendeu com a instalação da república no Brasil, mas que lamentou não terem possibilitado ao imperador filósofo o prazo necessário para que ele pudesse terminar a sua obra. A revolução, diz ele, foi uma "ingratidão" para com esse homem "venerado" (OLIVEIRA MARTINS apud COELHO, 1889, p. 366).

Carregado de anos e serviços, que consumiu a vida a dotar o seu império com os frutos de uma admiração em que a energia se aliou sempre à prudência, à força, à arte, alternando segundo as necessidades. Deixem-no morrer ao menos, acabar em paz o trono que era para ele uma mesa de trabalho: deixemno concluir a sua tarefa, de depois dessem largas à sua loucura! (COELHO, 1889, p. 366).

Gervásio Lobato, na sua "Crônica ocidental", publicada no Ocidente: Revista Ilustrada de Portugal e do Estrangeiro, também mostrou ao mesmo tempo consciência de que a república era inevitável e surpresa pela revolução não ter aguardado os últimos dias do imperador: 
Entretanto se a transformação por que acaba de passar o Brasil surpreendeu pela sua rapidez à Europa, ela não era de todo inesperada por quem seguia com atenção o movimento politico do Brasil nestes últimos tempos, e se ninguém esperava de fato que essa transformação se operasse agora, em vida do imperador, havia muito que a julgasse inevitável no dia em que o Imperador falecesse (LOBATO, 1889, p. 257-258).

Lobato saudou que "tudo isto foi feito pacificamente sem disparar um tiro. A população do Rio de Janeiro festejou o advento da república e quase todas as províncias do Brasil têm dado já a sua adesão ao novo governo". Além do que, considerou importante que o governo tenha declarado sua intenção de respeitar todos os compromissos, obrigações e contratos do estado e manter "a dotação ao Imperador deposto a que acompanhou com todas as atenções até bordo do paquete Alagoas em que no dia 17 seguiu para a Europa" (LOBATO, 1889 , p. 258).

Nesse mesmo teor, encontramos entre as linhas não assinadas do Ocidente a constatação de que "a julgar por estes telegramas a república proclamou-se em maré de rosas, sem resistência nem protestos, o que não pode deixar de abonar a habilidade dos conspiradores". Novamente, nesse mesmo artigo, encontramos comentários que reforçam a ideia de que a república já batia à porta do Brasil: "É certo que a república de há muito que pairava no céu do Brasil e era saudada com prazer pelos brasileiros" (NOTÍCIAS SOBRE A REPÚBLICA NO BRASIL, 1889, p. 264). Também não era novidade para os portugueses o respeito e carinho que o povo brasileiro nutria pelo seu imperador:

Mas tudo fazia crer que o seu advento só chegaria pela morte do imperador, a quem os brasileiros decerto quereriam poupar o desgosto de o destronar. $\mathrm{O}$ que, portanto, mais surpreendeu a Europa, não foi a república, foi o inesperado da sua proclamação, tanto mais depois das manifestações de respeito e simpatia tributadas pelo povo brasileiro e por todas as nações ao velho imperador, por ocasião do atentado frustrado contra a sua vida ocorrido há pouco (Revista política (NOTÍCIAS SOBRE A REPÚBLICA NO BRASIL, 1889, p. 264).

Nesse mesmo ano, e ainda no Ocidente, após uma grande ilustração de toda a família real, encontramos a sugestão de que esse ar pacífico que pairou por toda a revolução seria mais uma prova da relação afetuosa entre o povo brasileiro e Dom Pedro, "que soube fazer-se estimar e querer, não pela elevada jerarquia, não pelo eminente lugar que ocupava na cena do mundo, mas unicamente pelas suas eminentes qualidades pessoais, pelos seus elevados dotes de espírito e de coração". Somado a isso, a forma como soube lidar com os primeiro anos 
agitados de seu reinado fizeram com que caísse na graça do povo pela "sua simplicidade do trato, a suas virtudes domésticas, as poderosas qualidades do seu caráter e da sua inteligência lhe captaram toda a estima e consideração como homem" (A FAMÍLIA IMPERIAL, 1889, p. 275).

"O império brasileiro", disse Guiomar Torrezão, com uma certa dose de ceticismo, “se transformará de súbito, por uma hábil mutação de teatro, em república federal!”. Com um texto publicado em 1889, na Ilustração Portuguesa: Revista Literária e artística, a escritora engrossava a lista daqueles que se lamentaram antes de tudo pelo tratamento dado a Dom Pedro. Como lhe era costume, com uma escrita quase dramática, diz que "há palavras flageladoras, que nos torturam, ao escrevê-las, como se dentro da nossa pobre pena, inanimada e fria, batesse um coração!”. Torrezão, ainda que admitindo que a república pudesse representar a liberdade, a democracia e o primeiro passo para um futuro glorioso, insiste em dizer que os brasileiros deveriam ter mantido o "respeito" por aquele que ela chama de "inteligente e bondoso príncipe":

Mas para que esse direito se impusesse à nossa simpatia e afirmasse no futuro a nova fase gloriosa de uma nação livre, caminhando para o seu engrandecimento, era preciso que o Brasil não houvesse esquecido o respeito devido a esse inteligente e bondoso príncipe, a esse filósofo coroado, que folgava em descer os degraus do trono para ir procurar nos prêmios literários ou na habilitação do povo os homens superiores pelo talento; era mister que o Brasil venerasse nessa austera e dominadora figura de soberano democrático, profundamente devotado aos interesses da pátria, aquele que simbolizava a emancipação dos escravos, cujas mãos senis acabavam de expungir da fronteira do seu grande e opulento império a nodoa de sangue que havia tanto o maculava (TORREZÃO, 1889, p. 4).

Talvez a desconfiança de Torrezão fosse menos sobre a república e mais sobre a maturidade do povo brasileiro. Ela não deixa de admitir que a república, analisada "sob o domínio especulativo", ou seja, teoricamente, "não desflorada pelos atritos da prática" seria uma:

Heroica musa, vestida de alvo linho e aureolada pelos prestígios de uma revolução que despedaçou as algemas dos párias e reivindicou o sagrado e legítimo direito dos fracos, dos humildes, dos deserdados; a república, tal qual se representa ao nosso espírito, na esfera empírica da visão, é, sem dúvida, o mais admirável e abençoado regime que poderia brotar do cérebro humano para amparar e guiar no áspero caminho da terra as gerações que passam e as nacionalidades que surgem (TORREZÃO, 1889, p. 4).

Hist. R., Goiânia, v. 18, n. 2, p. 169-185, jul. / dez. 2013 
Contudo, complementa dizendo que para a maioria dos países, entre os quais se encaixa o Brasil:

\begin{abstract}
Não soou ainda a hora em que o homem, preparado pela lição da história e pelo tirocínio da vida, cientificamente e socialmente educado para a comunhão do credo democrático e da fraternização universal, se levante ao ideal de perfeição relativa, ideal concretizado, pelo menos em teoria, com a doutrina republicana (TORREZÃO, 1889, p. 4).
\end{abstract}

Ainda assim, se o Brasil queria entrar apara o time dos países modernos, avançados e republicanos, como já eram os Estados Unidos, Torrezão considera isso um erro, uma pressa, um equívoco, de que "história há de pedir-lhes [aos brasileiros] severas contas" (TORREZÃO, 1889, p. 4).

Jean Jaques Rousseau dizia que bastava ser rei para ser mau. Dom Pedro mostrou o contrário. Caetano Alberto, no Ocidente, em 1891, noticiando a sua morte, inicia seu artigo dizendo que o imperador "morreu destronado; morreu rodeado das simpatias dos próprios que o destronaram. Quanto vale o ser bom”. O último imperador brasileiro, segundo o jornalista, poderia ser chamado de arqueólogo, literato, poeta, mas, antes de tudo, a qualidade que mais se evidenciou foi a de filósofo, "ainda que tantas vezes sacrificada às imposições do elevado cargo que o destino lhes reservou". Foi ele "o primeiro democrata do seu povo, para não dizermos o primeiro republicano, e foi a vítima mais injusta do destino que lhe pôs uma coroa na cabeça" (ALBERTO, 1891, p. 274).

Depois de fazer um breve resumo dos primeiros e principais passos do imperador filósofo, Caetano destaca que sua superioridade era reconhecida por todo o país, e o Brasil podia orgulhar-se de ter um monarca "esclarecido, bondoso e (...) liberal por índole". Justamente por isso, todos os governos encontraram nele o mais verdadeiro apoio. Não bastasse, seria o "mais extremo defensor e apologista" da causa abolicionista (ALBERTO, 1891, p. 275). Ainda sobre seu enterro, Eduardo Schlobach Lucci, no Ocidente, ressaltou que "os monarcas, as tropas, os altos homens de política, da ciência, das artes, da literatura, do comércio, de todas as classes sociais, foram ao vasto templo de S. Vicente prestar as últimas honras a D. Pedro de Bragança, que lá estava inanimado no seu caixão coberto com a bandeira brasileira" (LUCCI, 1891, p. 281). 
Além das lamentações pelo destronamento de Dom Pedro, outra questão levantada mais de uma vez pelos jornalistas portugueses era saber se o surgimento de uma república federativa significaria o primeiro passo para a fragmentação do Brasil. Nas palavras do brasileiro Eduardo Prado, publicadas na Revista de Portugal, "continuará a existir a monarquia? Continuará a existir unido o Brasil? (...) A república e a fragmentação do país, são, aos olhos de uns, hipóteses inseparáveis. Ligadas como o efeito está ligado à causa; dizer monarquia, na opinião de outros, é dizer unidade nacional” (PRADO, 1889, 467).

Contudo, o articulista, diga-se de passagem, com ares de cientista social, tenta tranquilizar seus leitores, sobre as possíveis consequências mais graves dessa pacífica revolução brasileira. Apoiado em pontos de vista positivistas que tentavam definir, a partir da ideia de raça e temperamento, a reação do povo brasileiro diante dos novos acontecimentos, Eduardo Prado, em outras palavras, diz que se não fosse pela lentidão, lerdeza e calma inerente ao povo latino, seria possível que os incidentes decorrentes da revolução não tardassem a se transformar em maiores e mais desagradáveis consequências:

Daí um debate apaixonado acompanhando os incidentes diários de uma crise grave, fatal mesmo, se a inconsistência do moderno caráter latino em terra tropical, não desse garantia de que, por qualquer modo, com uma solução qualquer, ou talvez sem ela, tudo acabará em completa calma, por falta de persistência nervosa na massa da população brasileira e nas classes capazes de dirigi-la.

O momento de agora é psicológico na vida da nação brasileira. Numa raça em que as impressões são tão prontas quanto superficiais, embora as reações sejam tão lentas, como na raça brasileira, esse momento é muito breve (PRADO, 1889, 467).

Correndo o risco de sermos acusados de mal interpretar as palavras de Eduardo Prado, podemos dizer que o cronista sugere que o Brasil se salvou de uma possível desordem agitação social por conta da lerdeza e mansidão do seu temperamento. O futuro do Brasil, dizia Eduardo Prado, como bom positivista, estava intimamente relacionado à "obscura" "psicologia social" dos brasileiros. Portanto, todas as perguntas referentes à república, federação, fragmentação ou unidade do Brasil somente poderiam ser respondidas por aquele que conseguisse "avaliar as forças atávicas de destruição e as forças resistentes de conservação da sociedade brasileira atual, e para quem puder verificar se ela tem, não só vitalidade imanente e suficiente para conservar-se, como também energia bastante para progredir" (PRADO, 1889, 467). Sendo a ideia republicana a "forma mais aparente das 
tendências que chamaremos destrutivas" e a monarquia as forças de resistência (PRADO, 1889, 467).

Entretanto, o Brasil, segundo Eduardo Prado, como que sugerindo que a ideia de república estivesse fora de lugar, alega que o Brasil não estava preparado, ou mesmo era incompatível, com a reformulação e o regime imposto pela democracia federativa. Desde que se tornou independente, há mais de sessenta anos, o Brasil "recebeu" um sistema de governo complexo, que foi "amoldado pela adaptação lenta do seu desenvolvimento histórico":

Este é o fato culminante da existência política do Brasil, a anomalia inicial a que se prendem, mais ou menos, todas as inconsequências da vida política da nação. Desde a independência houve uma imensa desproporção entre o estado da civilização nacional e as aperfeiçoadas instituições dadas ao país. Enquanto o papel dos europeus daquele tempo era de criar governos bastante liberais para a civilização do povo, na América do Sul, a missão quase impossível dos diretores das novas sociedades políticas foi a de criar povos na altura das instituições livres, organizadas de proposito e aplicadas na ocasião.

Quem estudar a história do Brasil independente verá a desproporção entre a civilização real do país e o adiantamento das suas instituições originando um desequilíbrio sensível ainda hoje. Os algarismos demonstram que nenhum país dotado de um governo livre apresenta tão grande número de qualidades moralmente negativas quanto soa no Brasil os analfabetos, os rústicos isolados no interior e os representantes das raças inferiores ainda não extintas ou anuladas pela absorção na raça civilizada. Uma prova mais forte do que as estatísticas temos no fato de não ter sido a sociedade brasileira a que por mais tempo foi compatível com a escravidão, só por último abolida há apenas um ano. Por mais terreno que a civilização possa ter ganho no Império, não se pode pretender seriamente que o seu desenvolvimento tenha sido tal que o Brasil não possa mais suportar a monarquia constitucional representativa e sinta-se hoje acanhado dentro de uma forma de governo com a qual se contenta a alta cultura de tantos povos. É isto com tudo o que pretende a opinião republicana brasileira (PRADO, 1889, 467).

A república, assim com toda a movimentação política brasileira, para Eduardo Prado, seria uma expressão artificial de apenas uma parcela consciente de sua elite. O povo, de fato, estava completamente alheio às principais decisões tomadas pelos seus governantes. Como metáfora dessa situação, criativamente, o crítico toma o quadro A Proclamação da República, de Pedro Américo como imagem da dinâmica social-política brasileira. Na sua obra, o pintor foi capaz de retratar o "fato com toda a verdade e toda a filosofia". Eduardo Prado é inteligentemente irônico. Diz ele que podemos ver na pintura o príncipe regente, a cavalo, de espada desembainhada, cercada de sua guarda de honra, "dos gentis-homens de sua câmara, de vários capitães-mores" e que "no quadro há a vida admirável daquele momento histórico" 
(PRADO, 1889, 470). No entanto, o que mais lhe interessa, para metaforizar a participação do povo nas manifestações política no Brasil, é notar que no quadro há:

A um canto, um homem de cor guiando um carro, arreda dos seus bois da estrada e olha admirando para o grupo militar; ao longe, destacando-se no fundo iluminado de uma tarde que cai sobre a paisagem bucólica, um homem do campo, um caipira retém o passo à cavalgadura e voltando tranquilamente o rosto vê de longe, a cena que não compreende. Esse dois homens são o povo brasileiro, o povo real, a maioria da população que não participou da independência e muito mesmo toma parte na agitação republicana promovida em nome dele (PRADO, 1889, 470).

O que no Brasil se chama de movimento republicano, na verdade, seria apenas um movimento de "descontentes", que, não por coincidência, representam a classe de proprietários de terras e de uma parcela elitizada de poucos que tiverem acesso ao ensino superior - "homens feudais ou homens de pena (...) colocados acima do povo e do iletrado". Novamente, apelando para expressões, que não chegam a ser argumentos, Eduardo Prado diz que "nos países quentes e sem elevada organização moral, é um bilioso não refreado pela educação, sem a nobre faculdade respeitar, degredado na selvageria e linguagem porque lhe faltam músculos para manifestações mais viris de uma coragem em que não foi criado". Ainda que Eduardo Prado seja brasileiro, fizemos questão de mencionar alguns aspectos do seu artigo, pois ele foi publicado na importante e positivista Revista de Portugal. Em outras palavras, de uma forma ou de outra, a sua publicação num veículo tão importante denuncia que as suas análises sobre os últimos acontecimentos no Brasil encontraram coro e convergência com o que também uma parcela da inteligência portuguesa pensava sobre a república, a monarquia, o povo, a organização social brasileira e o seu "temperamento lento" (PRADO, 1889, 470).

No artigo, ao qual já nos referimos, publicado na Ilustração, em 1889, no qual Latino Coelho coleta diferentes opiniões sobre a república brasileira, ficamos sabendo que ele próprio problematiza a possibilidade da república ameaçar a unidade nacional brasileira.

São esses os dois grandes perigos da república brasileira, o desmembramento e a discórdia. Fundou-se a república sem efusão de sangue, dizem. É certo, mas isso deve-o o Brasil sobretudo a D. Pedro II, como a D. Pedro I deveu ter fundado quase sem efusão de sangue a sua independência (COELHO, 1889, $363)$.

Desmembrado, o Brasil perderia sua força e importância, deixando de ser para a América do Sul o que são os Estados Unidos para a do Norte. Para Latino Coelho, a calma 
que persistiu ao longo dos sessenta e sete anos da vida constitucional brasileira poderia ser fruto de três causas: da vontade de unidade da monárquica, da natureza pacífica do povo brasileiro ou, comparando ao que aconteceu nos demais países da América Latina, da superioridade do povo português que, antepassado dos brasileiros, se mostrou superior aos espanhóis que tiveram suas colônias sempre metidas em guerra.

Se puderem limitar o federalismo à concessão das necessárias regalias aos diferentes Estados em que se transformarão as atuais províncias, sem desmembrarem o Brasil, terão o aplauso de todos. Se o não souberem fazer, pesará sobre eles uma grandíssima responsabilidade, porque, por meras ambições, e por transigência com declamadores que acham mais sonora a palavra "república" terão sacrificado um governo sensato, prudente, a que o Brasil deveu a sua prosperidade e a sua força, um governo como o de D. Pedro II, a um governo incapaz de o substituir no desempenho da sua alta missão (COELHO, 1889, 363).

Latino Coelho tinha consciência de que a revolução republicana era menos um grito de liberdade e progresso e muito mais o espelho da ambição de um grupo já instalado e ainda mais desejoso de poder. Se os brasileiros, diz ele, forem capazes de limitar o federalismo a "concessões" e "regalias" às províncias, sem desmembrarem o Brasil, "terão o aplauso de todos":

O maior perigo da república está nos republicanos. Se ele souberem moderar as suas ambições, e ter a energia suficiente para manter a ordem e conservarem todos os elementos de prosperidade do Brasil, se souberem reagir contra os maus elementos que lhe deram uma vitória prematura, terão bem merecido da sua pátria, e bem merecido da humanidade (...) Se não o souberem fazer, pesará sobre eles uma grandiosíssima responsabilidade, porque, por meras ambições, e por transigência com declamadores que acham mais sonora a palavra "república" e terão sacrificado um governo sensato, prudente, a que foi o Brasil deveu a sua prosperidade e sua força, um governo como o de D. Pedro II, a um governo incapaz de o substituir no desempenho da sua alta missão (COELHO, 1889, 363).

Nesse mesmo artigo, retomamos a fala de Oliveira Martins, destacada por Latino Coelho, e ressaltamos também que esse desconfiava da unidade nacional, após a república. Ainda que considere que haja no novo ministério "nomes respeitáveis e simpáticos; nos seus primeiros atos, de que temos notícias, transparecem moderação, prudência e a possíveis deferências por tudo quanto ele próprio demoliu (...) Parece que a nova ordem não se estreitou mal; mas são tantas as dificuldades que terá a vencer, que a ameaçam indefinidas vicissitudes" (Oliveira Martins apud COELHO, 1889, p. 363).

Eduardo Melo França. NOTÍ́CIAS DA REPÚBLICA BRASILEIRA, E DA QUEDA DE UM IMPERADOR, NOS PERIÓDICOS 
Oliveira Martins, inclusive, supõe que o Brasil poderia vir a ser retalhado em pelo menos três "nações": "uma no vale do Amazonas, debatendo-se com a ingratidão do clima e com a própria riqueza territorial; outra no centro sob a hegemonia paulista; outra nas pampas do sul, porventura fundidos no Estado Oriental do Uruguai que é sobre o Rio da Prata, com Montevidéu, a capital geográfica da região" (OLIVEIRA MARTINS apud COELHO, 1889, p. 366).

Depois de instalada a república, não foram poucos os perfis, acompanhados de ilustração, que nossos primeiros presidentes e ministros receberam em importantes periódicos. Um desses saiu n'A Ilustração: Revista Quinzenal para Portugal e Brasil, em 1889. Nessa ocasião, além encontrarmos na capa do periódico uma grande ilustração do Marechal Deodoro da Fonseca, apresentado como presidente do governo provisório, lemos que ele desempenhou "grande papel" na revolução republicana; foi ele "o mais ativo e enérgico e se mostrou, pondo-se à frente da revolução (...) um verdadeiro soldado" (A REPÚBLICA DOS ESTADOS UNIDOS DO BRASIL, 1889, p. 358-359). Também receberam ilustrações e breves perfis: Benjamim Constant, Ministro da Guerra, tido como seguidor de Augusto Comte e considerado um dos "mais esclarecidos e independentes professores do Brasil". Quintino Bocaiuva, ministro dos negócios estrangeiros, foi destacado como "jornalista brilhante" "talentoso", "físionomia severa" e um "não sei que de triste e melancólico" (A REPÚBLICA DOS ESTADOS UNIDOS DO BRASIL, 1889, p. 358-359). Rui Barbosa, ministro da Fazenda, uma das "cabeças" do Ministério, pois desde sempre foi tomado pela sua "alta inteligência, solida e extensa ilustração, assim como pela autoridade pessoal que lhe é universalmente reconhecida" (A REPÚBLICA DOS ESTADOS UNIDOS DO BRASIL, 1889, p. 358-359). A Revista Quinzenal, em 1890, novamente publicou breves perfis de Eduardo Wandenkolk, ministro da Marinha, Aristides Lobo, ministro do Interior, e Demétrio Ribeiro, ministro da Agricultura.

Em 1889, n'O Ocidente, entre as ilustrações dos ministros Eduardo Wandenkokl, Campos Sales, Aristides da Silveira e Demétrio Ribeiro e uma ilustração que reproduz o momento no qual o povo, na rua do Ouvidor, ovaciona o Marechal Deodoro da Fonseca, lemos que "a população tocou o delírio, vitoriando o bravo general que se colocará à frente do movimento revolucionário" (A REPÚBLICA DO BRASIL/PROCLAMAÇÃO DA INDEPENDÊNCIA 1889, p. 283). Nesse mesmo ano, O Ocidente, além de trazer uma enorme ilustração de Deodoro da Fonseca, diz que ele seria tão festejado no Brasil quanto "Garibaldi 
entre os italianos e o nosso Saldanha entre os portugueses. Porque Deodoro da Fonseca é desses homens que se impõem pelos altos dotes de um coração de elite, e pela rigorosa observância do seu altruísmo" (ILUSTRAÇÃO DO MARECHAL DEODORO DA FONSECA, 1890, p. 258-259).

A morte de Deodoro da Fonseca não deixou de ser notícia em Portugal; com ela, caracterizar-se-ia a queda de uma das "duas colunas mais poderosas" da república brasileira, Deodoro da Fonseca e Benjamim Constant:

Os defensores ferrenhos da nova constituição do Brasil fundavam a proclamação da república na espada gloriosa de Deodoro da Fonseca e na ciência matemática social de Benjamim Constant, o que este preparara fora realizado por aquele; Deodoro da Fonseca era o braço, Benjamim Constant fora a cabeça (O MARECHAL DEODORO DA FONSECA. EXPRESIDENTE DA REPÚBLICA DOS ESTADOS UNIDOS, 1892, p. 202203).

No mesmo artigo, não assinado, lemos a seguinte pergunta:

A república fundada, inofensiva do outro lado do Atlântico à sombra do imperador, morta no quarto burguês de um hotel a que fora imperatriz, dispersa a antiga família reinante, Deodoro da Fonseca erguido à culminância política, aureolado o seu nome de todos os prestígios, livre o caminho de todos os embaraços, nada lhe tolhia a liberdade individual de consolidar a república pela forma que mais se harmonizasse com a sua vontade. Conseguiu-o? $(O$ MARECHAL DEODORO DA FONSECA. EX-PRESIDENTE DA REPÚBLICA DOS ESTADOS UNIDOS, 1892, p. 202-203).

Ainda que o próprio crítico diga que somente a "severidade" da história poderá responder a essa questão, ele se arrisca afirmando que Deodoro da Fonseca exercendo sua responsabilidade e autoridade "impediu com seu veto muitas das medidas decretadas pelo congresso nacional, e não é ocasião para averiguar se com esse veto impeditivo lucraram mais os interesses da pátria ou daqueles a que se estendiam a proteção presidencial" (O MARECHAL DEODORO DA FONSECA. EX-PRESIDENTE DA REPÚBLICA DOS ESTADOS UNIDOS, 1892, p. 202-203). O que é certo, diz ele, num tom cético e crítico, é que incontestavelmente, sob o seu governo, "a roleta do Acaso (...) levando na sua vertigem consciências e fortunas", enriqueceu "os que nada tinham, reduzindo à miséria os que pelo trabalho muito haviam amontoado, aproximando o Brasil, próspero até aí, da República Argentina, acabada de falir pelos excessos de jogo desenfreado" (O MARECHAL 


\section{DEODORO DA FONSECA. EX-PRESIDENTE DA REPÚBLICA DOS ESTADOS} UNIDOS, 1892, p. 202-203). Também no Ocidente, em 1895, fora noticiada a morte Floriano Peixoto, "um dos militares mais valorosos que se distinguiu nas campanhas do Paraguai (...) seu governo foi uma constante luta, que ascendeu a guerra civil e levou o luto e a desolação a todo aquele grande país" (FLORIANO PEIXOTO, 1895, p. 147).

Em 1893, saíam, no Ocidente, notícias sobre a insurreição no Rio de Janeiro. Após um período de "tranquilo refazimento das forças da nação", "depois de serenados os espíritos, mais inquietos pela transição havida no regime governativo do Brasil”, terríveis decepções emergiram; "assim, quando proclamada a república, as dissenções que se deram; agora, a insurreição que tem tomado a importância de uma guerra civil". A origem dessa "insurreição" seria a influência militar da anterior luta contra o poder imperial: "Uma vez que, convictos de que por si só poderão derrubar e elevar, os militares a seu bel-prazer insurgem-se e impõemse. É este o inconveniente das revoluções iniciadas ou feitas pelo elemento militar". E concluiu dizendo que "de uma revolução popular não provem estes perigos, eis, pois, a diferença" (ACONTECIMENTOS NO BRASIL, 1893, p, 234-235). Tudo teria sido agravado, segundo lemos no jornal, pois o marechal Deodoro "entendeu dever por à resolução parlamentar, negando a sanção ao decreto do congresso nacional que determinava sobre a eleição do presidente da União" (ACONTECIMENTOS NO BRASIL, 1893, p, 234-235). Ainda no Ocidente, nesse mesmo ano, em alguns números seguintes, lemos que essa revolta, assim como ocorre com certas doenças, teria entrado no período crônico, "um período terrível e de que não se pode prever o termo". Ficamos também sabendo que por esse tempo, no Rio, uma cantiga popular entrou em moda:

Custódio não vem à terra

Floriano não vai ao mar

Digam lá vocês, ó gentes,

Quando é que isso há de acabar (ACONTECIMENTOS NO BRASIL, 1893, p, 234-235).

A mesma desconfiança em relação ao papel desempenhado pela mão forte do exército no governo brasileiro foi explicitada por Eduardo Schlobach Lucci, no Ocidente, em 1891. Na sua coluna "Crônica ocidental", após alguns elogios à carreira militar de Floriano Peixoto, o comentarista diz que "entretanto é ainda o militarismo que domina o poder, e tanto basta para que não confiemos na tranquilidade do Brasil” (LUCCI, 1891, p. 281). 
Num pequeno texto publicado em 1894 n'O Ocidente, com ares de otimismo, lemos notícias sobre a eleição de Prudente de Moraes como o novo presidente do Brasil. Tal acontecimento seria o encarregado de trazer ao Brasil "esperança". Isso porque, em Portugal, como no Brasil, o novo presidente era tido como "respeitado em todo o Brasil", alcançando “boa reputação e popularidade, pelos seus elevados dotes de espírito e excelências de caráter”. Sua larga experiência com negócios públicos, "junta à vasta ilustração do seu espírito liberal, são tudo predicados que prometem um bom governo, que restitua ao Brasil a paz e todas as prosperidades de que é digno" (ILUSTRAÇÃO DE PRUDENTE DE MORAES, 1894, p. 114).

Enfim, as notícias portuguesas sobre a chegada da república no Brasil mostram que se o fim da monarquia era inevitável, o seu acontecimento basicamente girou em torno de dois eixos, relacionados um ao outro, Dom Pedro II e a unidade do país. A figura do imperador filósofo não despertava simplesmente admiração e respeito, levando quase todos a lamentarem que o novo regime emergisse antes que ele pudesse terminar seu trabalho. Dom Pedro, um estadista, antes de tudo, representava a possibilidade do país não se tornar refém dos interesses particulares daqueles que daí em diante, e até hoje, governam o Brasil.

Não seria um exagero dizermos que os textos visitados durante este artigo nos mostram que a crítica portuguesa teve a sensibilidade de perceber que a forma como se deu a mudança de regime no Brasil foi o primeiro passo para que o país saísse e, até hoje, não voltasse para os trilhos. Se Dom Pedro, aos olhos dos republicanos, positivistas e supostamente modernos, era o representante de um governo atrasado e antidemocrático, a instauração da república no Brasil, tal como se deu, aos olhos dos homens de bom senso, representou a negociação do estado brasileiro entre os latifundiários, o perigo da unidade federativa e, principalmente, a assunção ao poder de uma elite mais interessada em poder e lucro do que na construção de uma nação soberana e justa.

\section{The Proclamation of the Brazilian Republic and fall of the Emperor in the Nineteenth Century Portuguese Journals}

\footnotetext{
ABSTRACT: This essay undertakes a mapping of some of the top news published across the major Portuguese cultural newspapers of the nineteenth century about the installation of the Brazilian Republic.
}

Eduardo Melo França. NotícIAS DA REPÚBLICA BRASILEIRA, E DA QUEDA DE UM IMPERADOR, NOS PERIÓDICOS 
KEYWORDS: Dom Pedro; Republic; Brazil; Portuguese reader response criticism.

\section{REFERÊNCIAS BIBLIOGRÁFICAS}

ACONTECIMENTOS NO BRASIL. In: O Ocidente. Revista Ilustrada de Portugal e do Estrangeiro. Lisboa: Lallemente e Frères, 21 de outubro de 1893, v. 16, ano 16, n. 534, p. 234-235.

ALBERTO, Caetano. D. Pedro d'Alcântara de Bragança, ex-imperador do Brasil/Crônica Ocidental (notícias sobre o Brasil). In: O Ocidente. Revista Ilustrada de Portugal e do Estrangeiro. Lisboa: Lallemente e Frères, 11 de dezembro de 1891, v. 14, ano 14, n. 467, p. 274.

A FAMÍLIA IMPERAL. In: O Ocidente. Revista Ilustrada de Portugal e do Estrangeiro. Lisboa: Lallemente e Frères, 11 de dezembro de 1889, ano 12, v. 12, n. 395, p. 275.

A REPÚBLICA DOS ESTADOS UNIDOS DO BRASIL. In: A Ilustração: Revista quinzenal para Portugal e Brasil. Lisboa: Tipografia da Companhia Nacional editora, 5 de dezembro de 1889 , a. 6, v. $6, n^{\circ} 23$, p. $358-359$.

A REPÚBLICA DO BRASIL/PROCLAMAÇÃO DA INDEPENDÊNCIA. In: $O$ Ocidente. Revista Ilustrada de Portugal e do estrangeiro. Lisboa: Lallemente e Frères, 21 de dezembro de 1889, v. 12, ano 12, n. 396, p. 283.

COELHO, Latino. República dos Estados Unidos do Brasil. In: A Ilustração: Revista Quinzenal para Portugal e Brasil. Lisboa: Tipografia da Companhia Nacional editora, 5 de dezembro de 1889 , a. 6, v. 6, nº 23, p. 363, 366.

FLORIANO PEIXOTO. In: O Ocidente. Revista Ilustrada de Portugal e do estrangeiro. Lisboa: Lallemente e Frères, 5 de julho de 1895, v. 18, ano 18, n. 595, p. 147.

ILUSTRAÇÃO DO MARECHAL DEODORO DA FONSECA. In: O Ocidente. Revista Ilustrada de Portugal e do Estrangeiro. Lisboa: Lallemente e Frères. 21 de novembro de 1890. v. 13 , ano 13 , n. 429 , p. $258-259$.

ILUSTRAÇÃO DE PRUDENTE DE MORAES. In: O Ocidente. Revista Ilustrada de Portugal e do Estrangeiro. Lisboa: Lallemente e Frères, 11 de maio de 1894, v. 17, ano 17, n. 554 , p. 114.

Hist. R., Goiânia, v. 18, n. 2, p. 169-185, jul. / dez. 2013 
LOBATO, Gervásio. Crônica Ocidental. (Notícias sobre a formação do governo provisório no Brasil). In: O Ocidente. Revista Ilustrada de Portugal e do Estrangeiro. Lisboa: Lallemente e Frères. 21 de novembro de 1889, V. 12, ano 12, N. 393, p. 257, 258.

LUCCI, Eduardo Schlobach. Crônica ocidental. In: O Ocidente. Revista Ilustrada de Portugal e do Estrangeiro. Lisboa: Lallemente e Frères, 21 de dezembro de 1891, v. 14, ano 14, n. 468, p. 281.

MATTOS, Júlio de. Movimento republicano no Brasil. In: O Positivismo: revista de filosofia. Porto: Liv. Universal de Magalhães \& Moniz. Maio-junho de 1882, a. 4, v. 4, nº 3, p. 246.

O MARECHAL DEODORO DA FONSECA. EX-PRESIDENTE DA REPÚBLICA DOS ESTADOS UNIDOS. In: O Ocidente. Revista Ilustrada de Portugal e do Estrangeiro. Lisboa: Lallemente e Frères, 11 de setembro de 1892, v. 15, ano 15, n. 494, p. 202, 203.

PINA, Mariano. Crônica. In: A Ilustração: Revista quinzenal para Portugal e Brasil. Lisboa: Tipografia da Companhia Nacional editora, 20 de agosto de 1887, a. 4, v. 4, nº 16, p. 242.

PRADO, Eduardo. Destinos Políticos do Brasil. In: Revista de Portugal. Porto: Editores, Lugan \& Genelioux, 1889, v. 1, nº 4, p. 467.

REVISTA POLÍTCA (NOTÍCIAS SOBRE A REPÚBLICA NO BRASIL). In: $O$ Ocidente. Revista Ilustrada de Portugal e do Estrangeiro. Lisboa: Lallemente e Frères, 21 de novembro de 1889, v. 12, ano 12, n. 393, p. 264.

TORREZÃO, Guiomar. A República no Brasil. O Imperador D. Pedro II. In: A Ilustração Portuguesa: Revista Literária e Artística. Lisboa: Tipografia do Diário Ilustrado, 2 de dezembro de 1889 , a. 5 , v. $5, n^{\circ} 45$, p. 4. 